\title{
The Theory of Pay Effectiveness
}

\author{
Yao Li, Weihua Liu, Hao Li \\ College of Industrial and Commercial Administration, Tianjin Polytechnic University \\ Tianjin, 300387, China \\ E-mail: liyao821026@yahoo.cn
}

\begin{abstract}
The core function in human resource management is compensation management, and it is also the focus problem which brings the dispute and conflict between employers and employees. In this passage we will discuss some important factors of pay effectiveness.
\end{abstract}

Keywords: Compensation management, Pay effectiveness, Pay system

\section{Introduction}

Any enterprise takes pay system seriously and is eager to know how the validity of the pay system. But how to assess its effectiveness is a problem for the majority of enterprise. At present, many practices are that organizational performance is equal to the pay system, which is a simplified approach. Therefore, it reflects that there are no mature evaluation tools which can be applied to. Just thinking about it, if the organization evaluated the effectiveness of the pay system skillfully and accurately, the pay adjustment will have a decision-making basis and the determination of payment will have a direction.

\section{The conception of pay effectiveness}

Evaluation of effectiveness of the remuneration system is generally used the concept of pay effectiveness, which means the contribution of the remuneration system for the organizational strategy. Broadly speaking, it refers to the contribution made to the organizational performance and can motivate the staff to work. One of pay effectiveness research keystone is how to evaluation, which is to decide a standard for evaluation.

\section{The evaluation criteria of pay effectiveness}

At present, domestic researches in the pay effectiveness relatively are rare in the literature. In addition, the study of pay effectiveness has not formed a conclusion abroad, especially in the different areas. Firstly, several different views will be introduced here.

\subsection{View in Strategic Management field}

David and Luis measure the effectiveness of pay system with sixteen terms and four dimensions. They are general performance, recruitment performance, incentive performance and reservation performance. Firstly, the recruitment performance means that the recruitment could attract enough people of which number could pass the actual number of people. What's more, incentive performance means that the payment system could prompt the staff that needs encouragement. Finally, the employees should not leave their posts because of the salary.

The four areas which mentioned above establish a standard directly.

The final criteria are the organizational performance. Therefore, the organizational performance is one integral part of payment performance evaluation. In addition, it is often to regard the organization profit as one element of pay performance, from which we can clearly see that the evaluation of this field settled on the organizational level.

When Andrew S.Richter evaluated effectiveness of the pay strategy, he had proposed an integration model that was used to analysis the pay strategy (Andrew S.Richter, 2002, p30). From picture 1, we can clearly see that this model evaluates the pay strategy from three aspects, which are Value Proposition, Performance Differentiation and Cost Competitive. The index of value proposition means to the capacity of organization to attract and reserve person with ability. What's more, employees don't leave their post because of the payment. The index of performance differentiation means to pay employees according to their performance difference and to establish performance culture of the organization. The third index means that the organization should control the cost of payment and analyze the availability factor according to the budget.

The three layers reflect the basic objects of pay system which are market competitive and paying and controlling cost according to the performance difference. There are contradictions among the three layers. 


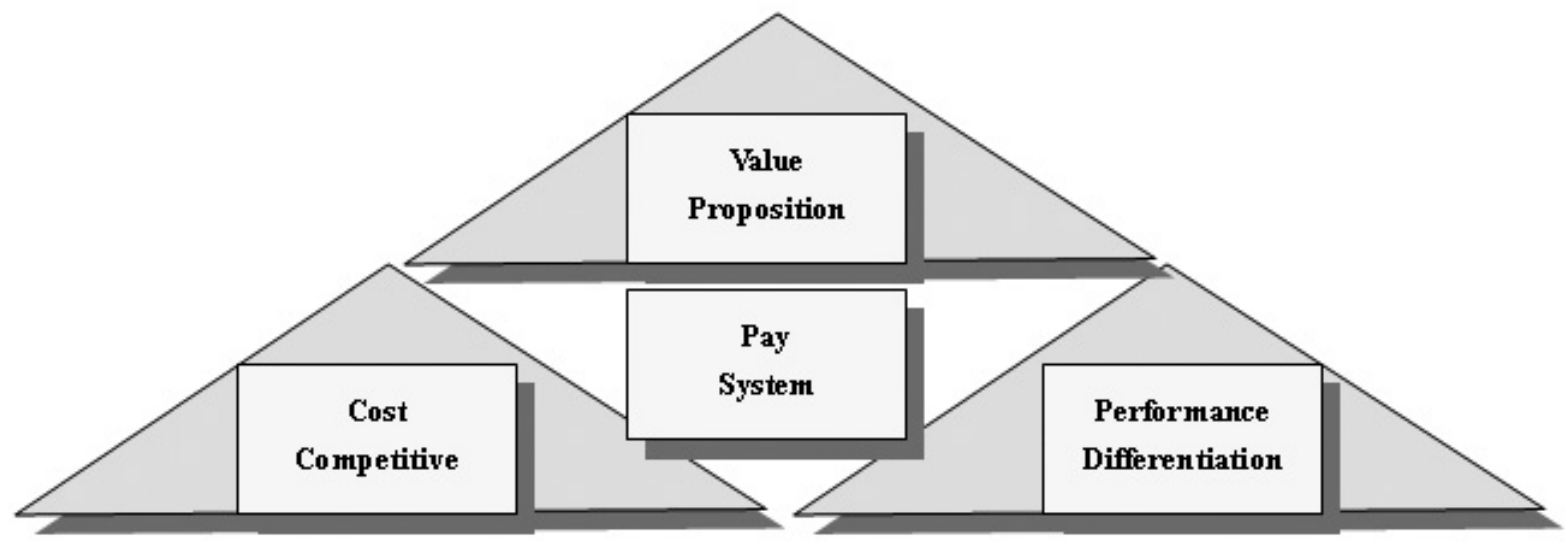

Figure 1. Integration Model of Analyzing Pay System (Andrew S.Richter, 2002, p30)

\subsection{Views in industrial psychology field}

When Luis R. Gomez - Mejia. David B. Balkan (1989) was researching the payment problems; he used four dimensions to evaluate pay effectiveness which contained the payment satisfaction, retreat cognitive, team performance and individual performance. What's more, because they researched the pay effectiveness of researchers whose salaries were based on the group, they reckoned team performance in the evaluation of pay effectiveness.

From the table of Minnesota Satisfaction Questionnaire (MSQ), we should use five projects to evaluate the pay satisfaction, which contained pay volume, level of pay policies, pay management, disbursement methods and incentive pay. In the field of industrial psychology, there were also other researchers who had put forward different views. They considered that the sense of equity was an important evaluation criterion. We should describe the sense of equity from four dimensions. When Jason A. Colquitt was proofing the dimension of equity sense, he brought forward four dimensions. They are process equity, allocation equity, interaction equity and information equity. Following expounds one by one.

\subsubsection{The equity of allocation}

The theory of allocation equity is that private person not only concerned about the absolute amount of the payment which is acquired through one's endeavor, but also be regardful of the relationship between the input-output of one's own and other's. They passed judgment on the relationship between own input-output and other's. In the base of that one person's input has been confirmed, they compared the outputs. When they thought the relationship was not fair, they would feel nervous. This nervous sense could become incentive base of the pursuant to the equity. Researches also found that the influence of high payment inequality was not significant. Obviously, compared with low salary inequality, people prefer to tolerating the inequality that caused by high salary. In other words, they could think high salary inequality is more reasonable.

\subsubsection{The equality of process}

Later, researchers found that the theory of allocation equality had a defect, namely, the equality theory put emphases on the result of salary allocation, but it had neglected the method which led to the result. On this basis, some researchers put forward the concept of process equality. Hereafter, Folger brought forward Referential Cognitive Theory (RCT) in regard to sense of salary equality. This theory supposed that the inequality sense was brought about by both result and process. At the same time, Folger discovered that the sense of salary is more important for people than the active result, and the sense of salary decide the sense of dissatisfaction. Therefore, if only the process inequality existed, the sense of dissatisfaction should give birth to.

\subsubsection{The equality of interaction}

Many researchers set forth the third category fairness, which is interaction equality. It means the fair sense, which the staff received in the working process. If the leader treated the staff with respect and circumspection and explained the decision to them, the interaction equality sense would engender.

\subsubsection{The equality of information}

The concept of information equality was firstly introduced by Greenberg. He thought that superior was send message to inferior when he asked for the opinions with regard to assessing the performance levels. At the same time, both sides would receive information through intercommunion. Therefore, Greenberg put forward to 
information equality. But, this concept has not been supported by demonstrations. In other words, this concept is a developing concept.

General speaking, there are some difference with regard to payment evaluation between industrial psychology field and strategic management field. The former settled in the organizational level, the latter settled in staff level. According to table 1 , it is no difficult job for us to find out the content of pay system. And these contents are the aspects of evaluating pay system.

Table 1. The Content of Pay System

\begin{tabular}{l|cc}
\hline \multirow{2}{*}{ Pay System } & $\begin{array}{c}\text { Organizational } \\
\text { Level }\end{array}$ & Pay Strategy, Pay Structure, Pay Policy, Pay Standard \\
\cline { 2 - 3 } & Staff Level & Pay Management, Equity Principle \\
\hline
\end{tabular}

\section{The factors of high effective payment}

There are several factors which lead to high effective payment.

\subsection{Meeting the special preferences of staff}

Different staff would have different preference of payment. Weaver discovered that different staff may have different sense of return. Firstly, he pointed out that the individual working return could measured by five factors, which are working, promotion opportunities, working guarantee, short working hours and salaries. On the one hand, it is found that workers prefer to external return, such as salaries. On the other hand, officers always pay close attention to internal return, such as working obligation. Ellen studied the return preference on sale managers of different level. He listed nine different anticipated returns, such as salary and obligation, bonus, additional bonus, stock, pension, promote opportunity, superior's attitude, respective sense and obtain of objective market. The results showed that low-level manager put more emphasis on bonus and pension, whereas, middle-level manager thought a lot of promotion opportunity. Luis R.Gomez-Mejia and David B.Balkin also found that the preference of salary project should be different because of the risk attitude. People who like risk actives prefer to floating salaries. It is useful for desire different salary plan to different staff to study different people's preference.

\subsection{Matching the organization's strategy and the pay system}

It is better to match the organization's strategy and the pay system. According to Gerhard and Milkovich's study of 500 enterprises, we can clearly found that different pay system could bring about the change of organization's performance. And, they also found that the organization's profit would increase because of the enhancement of the floating salary proportion. Therefore, it is focus problem to match the organization's strategy and the pay system in the salary field. David and Luis studied the relationship among pay system, organization characteristic and environment. They regarded developing stage of organization, vocation and organization's scale as the changing factors. An important conclusion had been set out was that the salary had been divided into two modes which were fixed one and floating one. We should establish salary system according to the management strategy.

\section{The reasons of high effective pay system}

It is useful for designing high effective pay system to find out the reasons which lead to high effective pay system. From the existing research, there are two reasons. Firstly, pay system improved the employment and labor relations, which brought about enhance of effectiveness. What's more, the working motivation of staff has been improved. We should analyze the pay effectiveness through the following form according to the above analysis. The format has been shown in picture 2 .

\section{Conclusion}

From what has been discoursed, we can find that the core function in human resource management is compensation management, and it is also the focus problem which brings the dispute and conflict between employers and employees. To a large extent, the total income of employees is determined by the pay system in the enterprise, so as to give effect on the living condition and the social status of employees. However, the high compensation expenditures for the enterprise do not spirit up employees' working motivation and attitude, on the contrary makes them critical of the enterprise. The enterprise is not clear with the investment effectiveness of this considerable amount for the expenditures of compensation costs. The illegibility for the effectiveness of the compensation investment which can not be measured brings the confusion for the enterprise administration.

Pay system effectiveness refers to the validity of the pay system, which means the contribution to the organizational strategy made by the pay system, and it represents the contribution to the organizational performance and the incentive degree for employees' working motivation. Any enterprise does greatly attach importance to the pay 
system, and also want to know eagerly how effective the pay system is of its own, but it is difficult for the most enterprises to evaluate the pay system effectiveness. It can be imagined that the decision of the compensation adjustment will be rational if the organization can proficiently and exactly evaluate the effectiveness of the pay system.

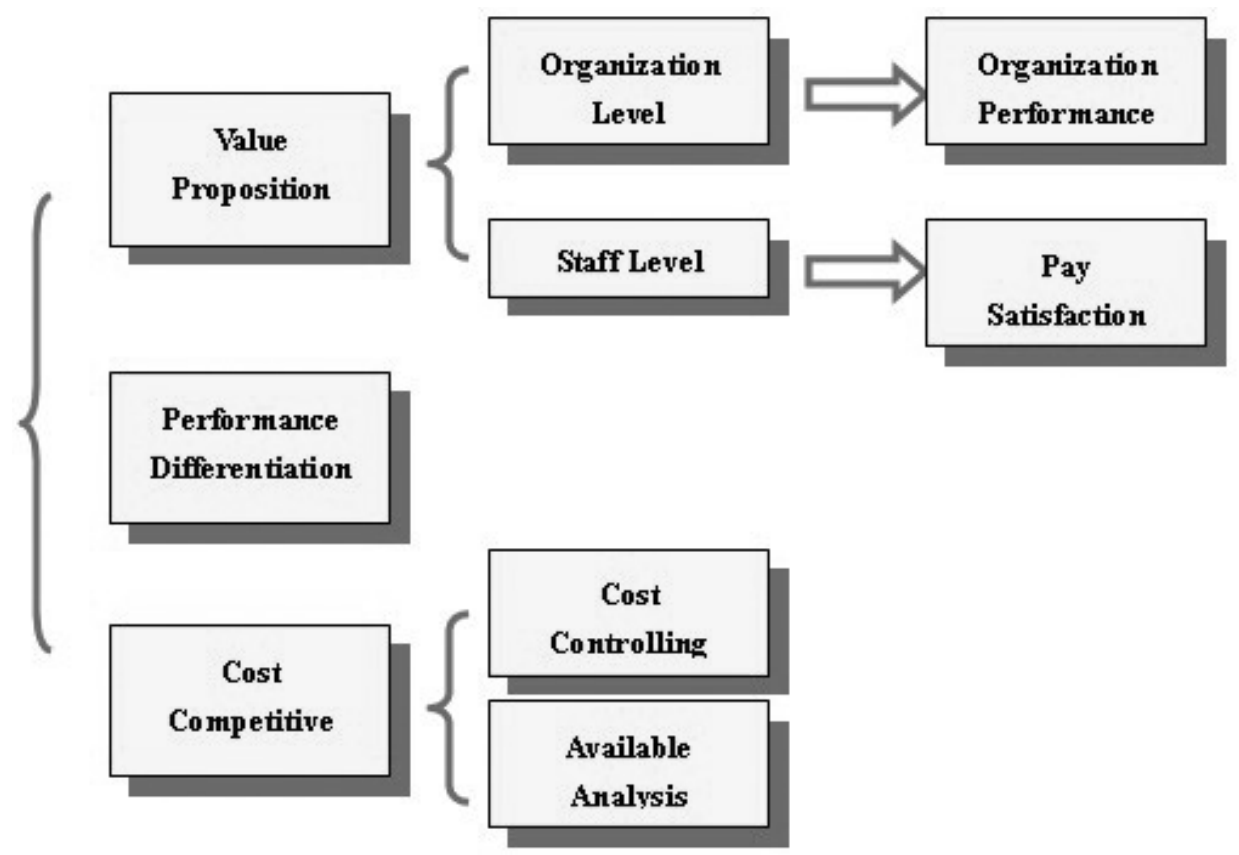

Figure 2. Analysis Format

\section{References}

[Chinese] Hu Yong \& Yu Shen (2002). The theory of pay effectiveness. Journal of Enterprise Economy, 12

Andrew S.Richter (2002). How does your compensation strategy measure up? Journal of Strategic HR Review. 3.P40

Heneman Robert L (2001). Business-driven compensation policies: integration compensation systems with corporate business strategies.American Management Association

J.Pfeffer (1994). Competitive advantage trough people. Boston, Harvard Business School Press 